\title{
Dinámicas transfronterizas en la música de acordeón y bandoneón del norte uruguayo
}

\author{
Dinâmicas transfronteiriças na música de acordeão e bandoneão no norte \\ de Uruguai \\ Cross-border dynamics in the accordion and bandoneon music of northern \\ Uruguay
}

\begin{abstract}
José A. Curbelo ${ }^{1}$
Resumen

A través de los testimonios de intérpretes de instrumentos de fuelle del norte de Uruguay, este artículo intenta examinar las dinámicas transfronterizas que han influenciado al desarrollo y trayectoria de la música de acordeón y bandoneón de esa región geográfica. También, intenta identificar al papel que el espacio de frontera compartido los países vecinos, Argentina y Brasil, ha jugado en la circulación de elementos culturales materiales e inmateriales que han sido incorporados a este fenómeno musical a lo largo de su historia.
\end{abstract}

Palabras claves: acordeón; Argentina; bandoneón; Brasil; frontera; Uruguay.

\section{Resumo}

A través das narrativas de intérpretes de instrumentos de fole do norte de Uruguai, este artigo tenta examinar às dinâmicas transfronteiriças que têm influenciado ao desenvolvimento e trajetória da música de acordeão e bandoneão desta região geográfica. Também, tenta identificar ao papel que o espaço de fronteira compartilhado com os países vizinhos, Argentina e Brasil, tem exercitado na circulação de elementos culturais materiais e imateriais que têm sido incorporados a este fenómeno musical ao longo de sua história.

Palavras-Chave: acordeão; Argentina; bandoneão; Brasil; fronteira; Uruguai.

\begin{abstract}
Employing narratives of players of free reed instruments in northern Uruguay, this article attempts to examine the cross-border dynamics that have influenced the development of the accordion and bandoneón music of this geographic region. The article also proposes to identify the role that Uruguay's border with Argentina and Brazil has played in the circulation of material and immaterial cultural elements that have been incorporated into this musical phenomenon throughout its history.
\end{abstract}

Keywords: accordion; Argentina; bandoneón; border; Brasil; Uruguay.

Desde la segunda mitad del siglo XIX existe un fenómeno cultural en el norte de Uruguay de música bailable de instrumentos de fuelle ${ }^{2}$. Esta música tiene sus raíces en la

\footnotetext{
${ }^{1}$ Mestrando; Programa de Pós-Graduação em Memória Social e Patrimônio Cultural da Universidade Federal de Pelotas; Pelotas Rio Grande do Sul, Brasil; curbelo@gwu.edu. Trabalho apresentado no I Seminário LatinoAmericano de Estudos em Cultura - SEMLACult, Foz do Iguaçu/PR, Brasil, 2017.

${ }^{2}$ Musicólogo uruguayo Lauro Ayestarán afirma que 1852 fue la fecha en que el acordeón de botón fue introducido al Uruguay (1968, p.65-66). Estaba compuesto de una hilera de botones. Más tarde llegó la versión
} 
mezcla cultural multiétnica de la región rural al norte del Río Negro que divide a ese país, una región de confluencia y conflicto histórico entre los mundos hispanoparlante y lusófono. Sus ritmos tradicionales como: polca, habanera, y mazurca son adaptaciones locales de música popular del siglo XIX y principios del siglo XX introducidas al Uruguay por medio de los grandes centros urbanos de la región (AYESTARÁN, 1968, p.27).

Esta tradición musical es de transmisión oral, aunque también se ha destacado la importancia de las radioemisoras del interior del país, desde las primeras décadas del siglo XX, en su transmisión. (FORNARO, 1994. p.71) Esta música ha servido como motivo de socialización en comunidades rurales por medio de bailes sociales en eventos como fiestas familiares, kermeses de escuelas rurales, velorios de santos, carreras de caballos, festivales, etc. (MENDOZA DE ARCE, 1972, p.190).

A través de testimonios de músicos uruguayos, este artículo comienza a analizar a las dinámicas transfronterizas que han tenido un impacto en la historia y desarrollo de la tradición musical de acordeón y bandoneón de la región norte del Uruguay, una tradición que fue tópico de una tesis de maestría defendida por el autor en junio 2017 en el Programa de PósGraduação em Memória Social e Patrimônio Cultural de la Universidade Federal de Pelotas. La justificativa de este esfuerzo investigativo es que sería imposible intentar entender a este fenómeno musical regional a través de un prisma nacionalista limitada solamente al Uruguay y la cultura irradiada desde su capital macrocefálica, Montevideo. La descripción de Cooley (2005, p.6) de la historia de la música de la región fronteriza de Polonia donde él realiza su investigación es aplicable al norte uruguayo: "es una historia no de aislación y pureza sino una de contacto y redes trans-regionales [...] y trans-nacionales, e historias compartidas y contestadas".

Este artículo se estructura de la siguiente forma: Primero, se intenta explorar a las perspectivas de distintos investigadores uruguayos sobre el contexto geográfico e histórico del norte uruguayo, la región que dio luz a la expresión musical que es nuestro objeto de investigación. Segundo, se realiza una corta revisión teórica que incorpora perspectivas de investigadores uruguayos que más han producido conocimiento académico sobre aspectos de

de dos hileras de botones y ocho bajos, que se convirtió en el modelo preferido por los músicos rurales de Uruguay. A principios del siglo XX el bandoneón empezó a difundirse y brindaba más posibilidades armónicas y melódicas, con setenta y un botones bisonoros, que como con el acordeón de botón, cada botón individual produce dos tonos distintos según si el músico esté cerrando o abriendo el fuelle. Más tarde en el siglo XX se popularizó el acordeón a piano. (DUNKEL, 1993) 
esta tradición musical, Lauro Ayestarán y Marita Fornaro, y también examina las particularidades de regiones de frontera. Tercero, se describe a la metodología utilizada en la investigación. Al final, se presentan los testimonios de los músicos entrevistados sobre dos vectores importantes de transmisión de esta tradición musical donde es posible identificar dinámicas transfronterizas: la familia, y la oralidad mediatizada posibilitada por grabaciones y la radiodifusión. También se presentan perspectivas de los músicos sobre la circulación de los aspectos materiales e inmateriales de esta tradición musical dentro de la región de frontera ${ }^{3}$.

La República Oriental del Uruguay actualmente comparte más de 1,100 km de frontera terrestre, fluvial y lacustre con el estado brasileño de Rio Grande do Sul ${ }^{4}$. Su frontera oeste está delimitada por el Río Uruguay sobre el cual comparte $500 \mathrm{~km}$ de frontera fluvial con la República Argentina, más específicamente con las provincias litoraleñas de Corrientes y Entre Ríos 5 .

Según la Oficina de Planeamiento y Presupuesto (OPP) de la Presidencia de la República la nación uruguaya está dividido en siete regiones ${ }^{6}$. Las que nos interesa en esta investigación son las regiones denominadas por el OPP como "Norte" (abarcando los departamentos de Artigas, Tacuarembó, Rivera y Cerro Largo) y "Litoral" (Salto, Paysandú y también Río Negro) que comprenden la gran mayoría del área fronterizo con Brasil y la Argentina (AROCENA, 2011, p.31). En este artículo la denominación "norte uruguayo" es empleada para referir a la aglomeración de las regiones Norte y Litoral según el OPP.

\footnotetext{
${ }^{3}$ En este artículo se utiliza el término "frontera" de la forma propuesta por Dominzain, et al. (2011, p.5) quien escribe:"[...] la inclusión del término "frontera" ha sido pensada, no en el sentido estricto del límite geográfico sino en el entendido de áreas de influencia que exceden al ámbito territorial fronterizo y cuya incidencia atraviesa notoriamente el entramado social."

${ }^{4}$ Servicio Geográfico Militar del Uruguay

${ }^{5}$ Comisión Administradora del Río Uruguay

${ }^{6}$ Uruguay está conformado por 19 departamentos, cada uno con su capital departamental: Montevideo, Canelones, Flores, Durazno, Florida, San José, Colonia, Soriano, Salto, Paysandú, Río Negro, Artigas, Tacuarembó, Rivera, Cerro Largo, Maldonado, Lavalleja, Rocha y Treinta y Tres.
} 


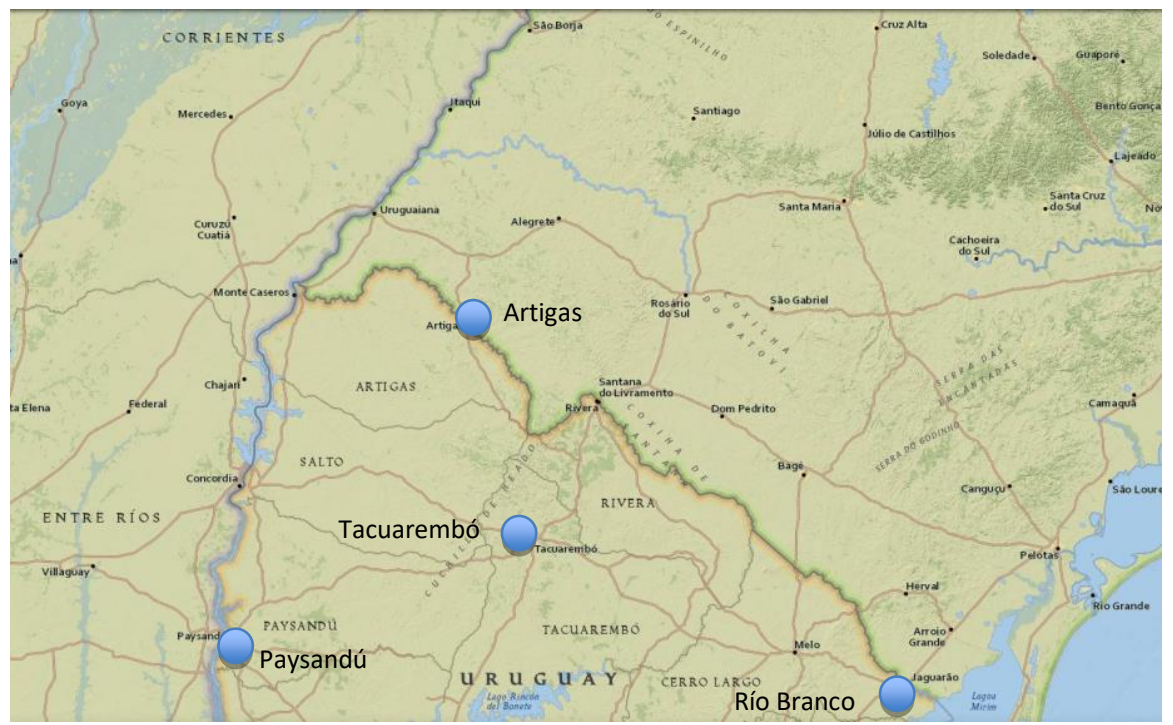

Figura 1 - Mapa del norte uruguayo y países limítrofes. Las ciudades de los informantes son identificadas Fuente: ESRI

Una característica importante del norte uruguayo actual es que la gran mayoría de su densidad poblacional se concentra en una suerte de "faixa de fronteira"7 limítrofe con los países vecinos Brasil y Argentina. Esta dinámica ha producido que, a lo largo de la historia, la población del norte uruguayo ha estado constantemente en yuxtaposición y contacto con las sociedades y culturas de los países vecinos.

Pellegrino describe al contexto colonial del territorio comprendido dentro del actual país de Uruguay que llevó a la conformación de una especie de "país casco":

Ubicada entre los grandes imperios coloniales de España y Portugal, la Banda Oriental fue escenario de movimientos migratorios que tenían como principal objetivo obtener territorios y fundar pueblos en zonas lindantes que permitieron avanzar sobre las líneas fronterizas de cada uno de los dominios europeos. (PELLEGRINO, 2013, p.11)

Pi Hugarte y Vidart añaden que:

El hecho de que nuestro territorio, conquistado y colonizado por los españoles, lindara con los ocupados por los portugueses, dio a nuestra formación histórica un sesgo particular, caracterizado por la fricción de intereses expansionistas opuestos, cuyas consecuencias llegan al presente [...] nuestro acaecer nacional se desenvuelve dialécticamente entre el destino de puerto y el de frontera, términos que indican el origen de los aportes principales a nuestra cultura: los extra-americanos y los procedentes de un interior cultural que resultan de la adaptación de la cultura portuguesa de conquista a los distintos contextos nativos, africanos y europeos no ibéricos. (PI HUGARTE, VIDART, 1969, p.40)

\footnotetext{
7 "Faixa de fronteira" es un concepto de la legislación nacional brasileña que la define como la "faixa interna de $150 \mathrm{~km}$ de largura, paralela à linha divisória terrestre do território nacional" y se considera de interés estratégico. Fuente: Instituto Brasileiro de Geografia e Estatística
} 
Debido a su historia, el área comprendida dentro del territorio actual de la República Oriental del Uruguay, un producto de la diplomacia británica del siglo XIX, puede ser considerada un área "tapón" ${ }^{8}$. Dentro de sus varias definiciones en el ámbito de las relaciones internacionales, una es de un estado que amortigua a la rispidez entre dos países vecinos más grandes y poderosos, un país tapón puede ser conceptualizado de la siguiente manera:

\begin{abstract}
Un país (que) evoluciona en un país tapón separando o conectando a dos esferas culturales. Por ejemplo [...] Uruguay (influenciado) por las culturas portuguesa y española [...] De este modo países tapones por mayor parte poseen características lingüísticas, étnicas, y religiosas de dos o más culturas [...] (o) civilizaciones, y pueden servir como puentes entre ellas. (TURMANIDZE, 2009, p.14)
\end{abstract}

La región norte del territorio uruguayo, demarcada más o menos por el Río Negro, que divide al país, se caracteriza mayormente por su matriz productivo de latifundios agropecuarios y la influencia histórica del Brasil. Escenario de luchas por territorio y poder entre imperios, estados, caudillos, y otros actores desde la época colonial, la importancia de esta región de frontera para la formación del estado uruguayo es descrita por Real de Azúa de la siguiente forma:

La frontera, en cuanto zona de indefinición de jurisdicciones, de intensa movilidad horizontal [...] pesó mucho en el curso histórico del país. [...] La historia uruguaya está tan henchida como cualquier otra de esta alta cuota de muerte, violencia, miseria y sufrimiento injusto que ha sobretejido suntuosamente la textura de la vida de los pueblos. (REAL DE AZÚA, 1984, p.13, 18)

Esta indefinición cultural y jurídica que reinaba en el norte hasta la segunda mitad del siglo XIX, dentro de la "textura de la vida" de sus habitantes (utilizando las palabras de Real de Azúa), produjo ciertos fenómenos culturales como la mezcla del idioma portugués con el español, llamado de "fronterizo" por Simões Larbanois, hija de poeta riverense Olyntho Maria Simões. Ella explica que:

El fronterizo es la resultante de un proceso histórico-geográfico que comienza antes que el establecimiento en la frontera de los primeros colonos españoles, pues ya a fines del siglo XVII pobladores provenientes del Brasil se habían establecido en nuestro país. (SIMÕES LARBANOIS, 1970, p.42)

Pi Hugarte y Vidart definen los límites territoriales de la influencia poblacional brasileña en territorio uruguayo de la siguiente manera:

La difusión de la subcultura lusobrasileña meridional se hizo sentir más profundamente en la zona de los departamentos de Artigas, Rivera, y Cerro Largo sin prejuicio de afectar vastas regiones de Tacuarembó e incluso dejar su impronta en el este de Salto. (PI HUGARTE, VIDART, 1969, p.41-42)

\footnotetext{
${ }^{8}$ Del término Buffer State en inglés
} 
Favre (2011, p.116) escribe que, "a lo largo del siglo XIX los brasileños obtuvieron un neto predominio sobre ese extenso espacio norteño que consideraron parte del Imperio". Agrega que, "la influencia de origen brasileño en la población era casi absoluta en todos los órdenes de la vida, incluyendo los aspectos policiales, judiciales, y educativos" (Ibid. p.66).

A raíz de estas presiones históricas de parte de su vecino del norte, con sus raíces en la rivalidad geopolítica luso-española de la época colonial, en el siglo XIX el establecimiento de núcleos urbanos en el norte uruguayo, en la mayoría de los casos, fue por iniciativa del gobierno central de Montevideo por "necesidades político-militares" y "siempre teniendo al mismo fin que había preocupado a sus antecesoras en la colonia: controlar el territorio". (RIAL, 1984, p.14, 26)

Pellegrino describe este proceso como:

(En 1851) ha terminado la Guerra Grande [...] se inicia la lenta tarea de a reconstrucción del país, inspirada en la idea de la fusión nacional. El gobierno de la República pone en práctica su nueva política de protección de fronteras y población de la campaña orientándose a la fundación de pueblos fundamentalmente fronterizos, que frenen la penetración e influencia de Brasil. (PELLEGRINO, 2013, p.7)

La región litoral del norte uruguayo, con las ciudades ribereñas de Salto y Paysandú como sus polos más relevantes, fue escenario de varios de los más importantes conflictos de la época artiguista. La importancia del sistema fluvial para el proceso de poblamiento de esta región es resumida por Rial como:

Durante el siglo XIX, antes de estructurar la red ferroviaria, los corredores principales por donde se desplazaban bienes y hombres eran los ríos [...] Salto y Paysandú compitieron como centros de distribución comercial llegando a conformar polos regionales al norte del Río Negro, pujando a su vez, con las ciudades situadas al otro lado del río. (Ibid., p.25)

La importancia estratégica del Río Uruguay ayudó a formar profundos lazos con la Argentina y su gran capital Buenos Aires, y la región pudo traer:

[...] inmigrantes de las más diversas nacionalidades europeas, muchos de ellos movidos por un fuerte espíritu empresarial que transformó a esas tierras en un escenario privilegiado de un progreso material y cultural desconocido en el resto del país. (PADRÓN FAVRE, 2011, p.122)

También la región litoral, por muchos años, recibió migrantes argentinos. Sobre el caso de Paysandú, Ostuni escribe:

El contacto con la Argentina fue notorio en el siglo XIX, el pasado histórico era común y el Río Uruguay una vía de unión obligada. Esa relación, con repercusión de orden cultural [...] se materializó con la presencia de argentinos que [...] llegaron a Paysandú. (OSTUNI, 1970, p.51)

Pi Hugarte y Vidart también escriben que: 
Los intercambios humanos y culturales trans-uruguayos han tenido lugar preferentemente en los departamentos del litoral, cuya vinculación histórica en lo social, económico y político con las provincias argentinas es por demás conocida. (PI HUGARTE, VIDART, 1969, p.38)

En cuanto a la relación del litoral con las metrópolis porteñas: Montevideo y Buenos Aires, Peña y Campal escriben, en el caso de Paysandú:

Paysandú, con una situación predeterminada, sufre como todas las localidades del interior, la influencia negativa de la creciente macrocefalia. [...] En el caso del litoral expuesto, asimismo, a la influencia argentina, en particular bonaerense. (PEÑA, CAMPAL, 1970, p.30)

Teixiera de Scirgalea et al. describen a lo que ellas ven como determinantes geográficos que fueron claves en la conformación de la sociedad de Salto:

El factor geográfico influye en la formación del carácter local: 1.) Por su situación, Salto se encuentra en el punto de contacto de tres sociedades (uruguaya, brasileña, y argentina) y cada una le aporta su modalidad. [...] 2.) Por su aislamiento de la metrópoli que le permite desarrollarse con independencia de Montevideo. (TEIXIERA DE SCIRGALEA ET AL., 1970, p.23)

El norte uruguayo se mostró resistente al proceso nacionalizador promovido por el centralismo montevideano en las últimas décadas del siglo XIX (PADRÓN FAVRE, 2011, p.81-82). Esta nacionalización se expresó a través de ampliación de infraestructura, expansión de poder administrativo-militar, y también se expresó en el ámbito educativo-cultural. Padrón Favre contextualiza que:

[...] muchas de estas medidas tenían también como objetivo ejercer una verdadera nacionalización del territorio ante la gran influencia que la población de origen brasileño poseía sobre una vasta porción del país [...] fueron muchas las voces que durante varias décadas se levantaron para señalar esa amenaza a la soberanía nacional. (PADRÓN FAVRE, 2011, p.66

Colonizado por el imperio portugués y posteriormente por el imperio brasileño, en condición de Provincia Cisplatina, la actual República Oriental del Uruguay, después de la consolidación de su independencia, embarcó una campaña de consolidar su territorio que estaba bajo influencia luso-brasileña. Según De Larrobla Et Al.:

En la temprana vida de la República se documenta la inquietud que provoca esta población extranjera en la zona norte del país [...] mientras dolorosamente se va plasmando la patria oriental. [...] Montevideo, lejana y separada durante muchos años a causa de sus precarios medios de comunicación, poco podía aún, hacer sentir su influencia, y los contados centros urbanos creados en la zona, eran todavía muy débiles para actuar con eficacia. (DE LARROBLA, ET AL., 1982, p.11, 19)

Estas confluencias y conflictos a través de la historia entre estados, culturas y sociedades ocurridos dentro de la geografía que hoy conforma el norte de Uruguay son de alguna manera reflejadas en la tradición musical del acordeón y bandoneón de esa región. Elementos de cultura inmaterial y material filtrados por la frontera, en otros tiempos más 
difusa y contestada, se fueron incorporando a este fenómeno musical hasta darle la forma que tiene en la actualidad. Estas influencias y dinámicas transfronterizas son expresadas en las propias vidas e historias de los ejecutantes de esta expresión musical y las de sus comunidades en estas regiones de frontera del norte uruguayo. Pi Hugarte y Vidart (1969, p.40) escriben, "Cultural e históricamente esta frontera no coincide con las líneas de división política; uno y otro territorio han estado siempre sometidos a influencias recíprocas".

También en esta línea de pensamiento, Lauro Ayestarán (1913-1966) investigador pionero de la música uruguaya, escribió, "todos los países de América comparten con sus vecinos sus especies populares. El folklore se ríe de la geografía" (AYESTARÁN, 1997, p.19). En su clasificación de la música tradicional uruguaya en "grandes ciclos folklóricos" Ayestarán (Ibid., p.6) destaca al carácter transfronterizo de dos de ellos: "1 ${ }^{\circ}$ ) un ciclo de danzas y canciones rurales rioplatenses que forma una unidad folklórica con las provincias argentinas de Buenos Aires y Entre Ríos [... 2 2 $)$ un ciclo norteño que participa, juntamente con el Estado brasileño de Río Grande del Sur".

Este último, denominado el "Cancionero Norteño" fue revisitado y ampliado por Marita Fornaro en los años 1990. A base de análisis del material de campo de Ayestarán, ella escribe:

El llamado 'Cancionero Norteño' coexiste con los restantes cancioneros en el área fronteriza $[\ldots]$ además de las especies que son específicamente atribuidas a este cancionero, deben tomarse como parte de él modalidades riograndenses de especies presentes en diferentes regiones de América. Tal es el caso de la polca, la mazurca [...] el shotis, el vals. [...] en cuanto a organología, el acordeón de dos hileras es protagonista de las especies coreográficas [...] (debe) mencionarse también [...] el bandoneón. (FORNARO, 1994, p.45)

Relatando sobre su propio trabajo de campo en los departamentos de Tacuarembó y Rivera, Fornaro destaca:

La importancia del uso tradicional de bandoneón [...] llama la atención [...] su recurrencia en la zona investigada, notoriamente mayor que el resto del país [...] En nuestro trabajo de campo hemos registrado en bandoneón, además de tangos, milongas y valses, rancheras, mazurcas, shotis, marchas, baiones, sambas. En Tacuarembó y Rivera es el instrumento preferido, junto con el acordeón de doble hilera, para ejecutar las tan apreciadas polcas del norte. (FORNARO, 1994, p.63)

Sobre esta polca del norte, fenómeno musical que surgió en esta región, Fornaro (1994, p.57) sostiene, "consideramos esa influencia (la de Brasil) la explicación técnica de la especificidad mencionada". Ella también identifica a la transmisión oral pura y la transmisión oral mediatizada como las vías de transmisión más importantes en los resultados de su trabajo de campo sobre la música de acordeón y bandoneón del norte uruguayo. (Ibid., p.71) 
Sobre el concepto de oralidad mediatizada, Paul Zumthor sostiene que la oralidad puede clasificarse en las siguientes divisiones:

[...] una oralidad primaria, sin contacto con forma alguna de escritura; una oralidad mixta, que coexiste con la escritura en un contexto sociológico [...]; una oralidad secundaria que en realidad se recompone a partir de la escritura (la voz pronuncia lo que antes se ha escrito o se ha pensado en términos de escritura) en un ámbito donde, tanto en la práctica social como en la imaginación, predomina lo escrito sobre la autoridad de la voz; una oralidad mediatizada, la que hoy nos ofrecen la radio, el disco y otros medios de comunicación. [...] En cuanto a la oralidad mediatizada, hoy coexiste con la tercera o la segunda, e incluso, en algunas remotas regiones, con la primera. (ZUMTHOR, 1985, p. 5)

En el caso de esta tradición musical se ve claramente la coexistencia de estas distintas variedades de oralidad con melodías y estilos transmitidos vía oralidad primaria ("pura"), secundaria vía partituras (por mayor parte en el caso del bandoneón y la música típica rioplatense), y oralidad mediatizada.

La radiodifusión, el vector de transmisión oral mediatizada más importante en nuestro objeto de investigación, tiene una larga historia en el Uruguay. La primera emisora fue puesta en operación en el año 1922 en Montevideo, y no demoró mucho en ver la expansión de otras emisoras en la capital e interior del país. Fornaro (2005, p.144) observa que, "Este temprano desarrollo de la radiodifusión en el país significa una rotunda modificación del paisaje sonoro doméstico, en el que, hasta entonces, predominaba la música interpretada por la familia, ya por transmisión oral o a partir de la partitura".

Según Fornaro (2005, p.145), "La radio tuvo una inmediata consecuencia en el consumo de música, ya que permitió una mayor difusión de la producción local e internacional" que sobrepasaba la difusión por medio de la venta de discos de pasta, un producto que era difícil para las clases populares mantener un consumo habitual. Ella observa que, "Uruguay fue clara periferia de Buenos Aires en cuanto a la grabación de estos discos, ya que hasta la década de 1940 no se editan comercialmente discos en el país". (Ibid.) Además de música grabada un componente importante de la programación de las radios eran actuaciones musicales en vivo.

La investigadora destaca al creciente papel de los medios de comunicación en la música popular uruguaya a lo largo del siglo XX:

[...] la radio, el disco, y la casete se perfilan entonces como formidables agentes en la constitución de una identidad musical local, a la vez que vehículos de conexión con países y modas musicales que, sucesivamente, fueron integrando el imaginario de los uruguayos. (FORNARO, 2005, p.152) 
Ilustrando a las observaciones de Fornaro, Dominzain et al. (2011, p.5) descubrieron en su estudio del consumo cultural en la frontera uruguaya en 2011 que, "Especialmente se notó en las ciudades de frontera [...] que lo local/global interactúa visiblemente en el consumo de música [...] Estas zonas fronterizas dan cuenta de peculiares entramados socioculturales donde los países entran en contacto."

Esta observación sobre consumo de música refleja a la dinámica fronteriza actual del norte uruguayo en su límite con Brasil. Isabel Clemente sostiene que:

Aunque el enfoque geopolítico de la frontera tuvo muchos defensores en centros de análisis estratégico y estudios militares del Brasil, posee poco poder de descripción de la frontera uruguayo-brasilera. (CLEMENTE, 2010, p.167)

Citando Machado de Oliveira (2005, p.388) Clemente opina que:

[...] su caracterización de la frontera viva, que toma en cuenta la existencia de una densidad de población importante, de flujos continuos de intercambio de productos y de informaciones, relaciones, y códigos propios en las relaciones sociales resulta apropiada para el caso de la frontera uruguayo-brasileña. (CLEMENTE, 2010, p.168)

Machado de Oliveira (2005, p.388) define una frontera viva como una frontera con "alta integración formal (y) alta integración funcional. Fronteras vivas son [...] áreas típicas de tensión constante". Machado de Oliveira también explica una realidad que se aplica a las zonas fronterizas uruguayas:

Los fronterizos se parecen uno al otro y crean las condiciones necesarias para producción y reproducción de una localidad específica [...] Este ambiente plural transformó las fronteras en territorios singulares. Son singulares en relación al territorio-nación y singulares entre si - cada frontera es una frontera. (MACHADO DE OLIVEIRA, 2005, p.380-381)

También, como la historia demuestra, además de las fronteras políticas compartidas con los países vecinos, para el norte uruguayo existe una cierta "tercera frontera" que: "[...] no [...] refiere al país vecino sino a Montevideo, ciudad a la cual se la ve distinta y distante, de la que permanentemente se tratan de diferenciar" (RADAKOVICH, 2011, p.33).

Como su objeto de análisis, este artículo utiliza algunas historias orales resultantes de trabajo de campo etnográfico realizado a través de la Universidad Federal de Pelotas en 2016 y algunas entrevistas de los mismos informantes realizadas anteriormente por el autor en los años 2002 y 2003 como parte de una investigación independiente. Las entrevistas fueron realizadas en las siguientes ciudades de región de frontera: Paysandú, Artigas, Tacuarembó, y Río Branco.

Los informantes fueron escogidos por ser considerados referentes locales en la ejecución de música de acordeón y bandoneón que cuentan con trayectorias importantes en sus respectivos lugares de residencia. Se enfocó en las historias de vida de cinco informantes, 
todos tocadores de acordeón de botón, acordeón a piano, o bandoneón. Estas narrativas individuales conforman parte de la materia prima de la memoria colectiva de este fenómeno musical regional y son los elementos primordiales para el proceso de definir y contar la historia de esta música.

La lista de los entrevistados incluye:

- Walter Roldán (n.1943) (Tacuarembó)

- Intérprete de acordeón de dos y tres hileras. Heredero de una larga tradición familiar de acordeonistas. Desde joven tocó en los bailes en la zona rural aledaña a la ciudad de Tacuarembó. Fue instrumental en la organización de festivales de acordeón de dos hileras, y ha sido fundamental en el tránsito de este género musical a escenarios y festivales del país y del mundo en las últimas décadas con su colaboración con guitarrista Héctor Numa Moraes, y el grupo Los Gauchos de Roldán.

- Euclides Díaz (n.1955) (Tacuarembó)

- Intérprete de acordeón a piano y acordeón de dos hileras. Toca desde niño, y lidera una agrupación conformada por él y sus hijos que anima eventos bailables en la región de Tacuarembó.

- Marcelo Fagúndez (n.1967) (Paysandú)

- Intérprete de acordeón de dos y tres hileras que viene de una reconocida familia de acordeonistas del pueblo de Cerro Chato, departamento de Paysandú. Sobrino de acordeonista renombrado Bocha Fagúndez, actualmente toca en bailes, festivales y otros eventos con el grupo tradicional La Sinfónica de Tambores. Ha presenciado toda la trayectoria de este género, desde su expresión tradicional vía transmisión oral, su decaimiento, y hasta su "re-tradicionalización".

- Washington Montes (n.1960) (Artigas)

- Intérprete de acordeón a piano y teclado. Tiene décadas interpretando repertorios bailables variados, productos de la confluencia de países y culturas en la ciudad fronteriza de Artigas. Tiene profundo conocimiento de la dinámica de los bailes sociales recientes y del pasado y los factores que han dificultado su realización en las últimas décadas.

- Ernesto Farías (1948 - 2016) (Río Branco, Cerro Largo)

- Intérprete de bandoneón oriundo de Montevideo. Recibió una educación musical formal de la escuela de la música típica rioplatense y desde hace 50 años que vivía 
en la frontera entre Uruguay y el Brasil. Tenía décadas tocando en bailes sociales en la zona de Cerro Largo acompañado por otros músicos, con un gran enfoque en el tango.

- Jorge Medina (n.1956) (Paysandú, Uruguay)

○ Intérprete de bandoneón oriundo de Paysandú. Recibió una educación musical formal de la escuela de la música Academia Rubiolo en esa ciudad. De niño tocaba en bailes rurales en la provincia argentina de Entre Ríos y el interior del departamento de Paysandú. Actualmente toca en la Banda Municipal de Paysandú.

En cuanto a la influencia de la frontera y dinámicas transfronterizas en la transmisión de la música de acordeón y bandoneón del norte uruguayo se toman dos importantes vectores citados por los informantes: la transmisión intergeneracional que ocurre dentro de familias, y también la oralidad mediatizada, la transmisión oral que es mediado por dispositivos tecnológicos de difusión, en el caso de esta tradición musical, principalmente la radio y también discos grabados.

Los entrevistados fueron unánimes en afirmar la centralidad de la familia en la transmisión de esta tradición musical. Algunos destacaron la importancia de la incidencia de lazos familiares transfronterizos en su arte musical, siendo descendientes directos de argentinos o brasileños. Otros, no saben con exactitud el origen nacional de sus ancestros pero descienden de familias provenientes de zonas de fuerte presencia histórica de pobladores brasileños. Otro informante debe la presencia de su familia en la frontera a la iniciativa del gobierno central uruguayo de extender su dominio político-militar en el norte. Radakovich (2011, p.21) también destaca la centralidad del ámbito familiar en la transmisión de música tradicional en las ciudades de la frontera y sostiene que el lazo familiar es, "uno de los vínculos más fuertes [...] en que la tradición folclórica continúe".

La migración de familias brasileñas y argentinas al territorio uruguayo es un fenómeno de larga data. Según Pellegrino:

[...] en la década de 1830 [...] continuó la inmigración fronteriza de portugueses y argentinos, lo que en un territorio poco poblado, tuvo un impacto demográfico muy considerable. La ubicación del territorio uruguayo, constituido como frontera entre Argentina y Brasil [...] hizo que recibiera aportes migratorios de ambos países. [...] La inmigración europea se radicó fundamentalmente en la capital [...] Asimismo, la migración regional existió de manera permanente y la presencia de brasileños en el norte y de argentinos en el litoral y sur, constituyó un factor de impacto considerable en el crecimiento de la población de Uruguay en la segunda mitad del siglo XIX. (PELLEGRINO, 2013, p.11)

Teixeira de Scirgalea et al. describe a la influencia argentina sentida en el litoral, más específico, el departamento to Salto: 
Del otro lado del río recibimos dos corrientes [... 1.) La influencia correntina [...] debido al continuo intercambio existente entre las dos sociedades a causa de lazos familiares, culturales y económicos. 2.) La influencia porteña, debida a que, antes, las vías de comunicación facilitaban más el acceso a Buenos Aires que a Montevideo [...] (TEIXEIRA DE SCIRGALEA ET AL., 1970, p.31)

El caso del bandoneonista sanducero ${ }^{9}$, Jorge Medina, ilustra esta observación [Figura 2]. Medina (2016, p.14) explica que, "Mi padre era argentino de acá, la zona de Corrientes. Nacimos con el chamamé acá, entonces nos encanta el chamamé". ${ }^{10}$ Él cuenta sobre la gran importancia de la transmisión musical de familia:

Por parte de mi padre sí (son músicos). Parientes, primos y unos tíos de él que son argentinos de la parte de Corrientes, son músicos pero mi padre no, mi padre le gusta la música no más [...] Ellos son de la zona acá de la zona de Entre Ríos , de Colón, pero familiares más lejanos sí eran correntinos y eran todos músicos [...] (Tocaban) acordeón dos hileras, guitarra, tenían un grupo correntino, chamamé, toda esa música popular correntina [...] Hay dos primos de mi padre que viven acá en la ciudad de Colón que son músicos, hacen música correntina, folklore [...] Sí, por parte de mi mamá también (hay músicos), o sea, tíos de mi madre también tocaban la acordeón de dos hileras y la armónica [...] (tocaban) música también, correntina, o sea, chamamé y todas esas cosas [...] Ahora la familia por parte de mi madre, son todos uruguayos [...] Bueno, la mamá de mi madre, descendiente alemana de apellido Fischer, la mamá de mi madre y, bueno, por parte de mi padre, el apellido Medina, no sé, español...(MEDINA, 2002, p.1)

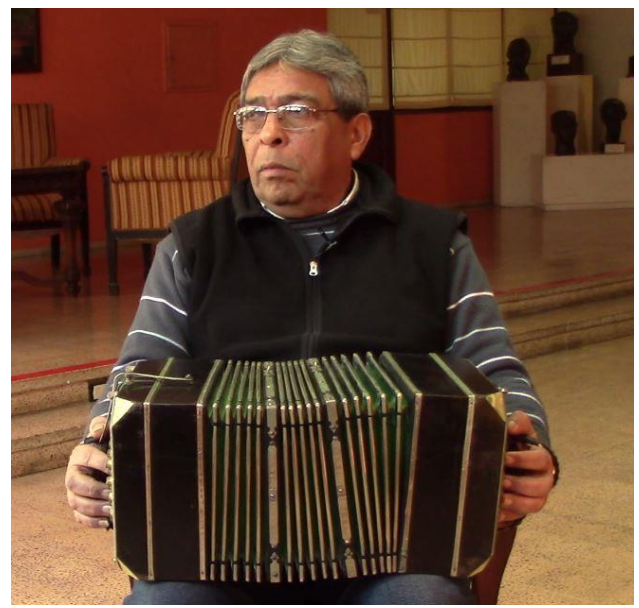

Figura 2 - Jorge Medina (Paysandú, 19 Julio, 2016) Foto: José A. Curbelo

\footnotetext{
${ }^{9}$ Término utilizado para referir a una persona oriunda del departamento de Paysandú.

${ }^{10}$ El chamamé es una expresión cultural popular de raíz tradicional rural que involucra música y danza, y proviene del litoral argentino, con la provincia de Corrientes como su epicentro. Los orígenes del chamamé son debatidos por varios expertos, pero se entiende que tiene cientos de años de historia y posee elementos de cultura guaraní, española, afro-criolla, y de culturas provenientes de la ola inmigratoria que experimentó Argentina en los siglos XIX y XX. Ya en las últimas décadas del siglo XX logró la consolidación como una expresión cultural musical y dancística bastante difundida por toda Argentina. Los principales instrumentos utilizados en este género musical son guitarra criolla, instrumentos de fuelle (acordeón diatónico, bandoneón, etc.), a los cuales muchas veces se incorporan otros instrumentos como contrabajo. Se baila en pareja enlazada y los pasos involucran zapateo por parte del hombre.
} 
Escribiendo sobre el contexto de Paysandú, Campal (1970, p.14) describe los factores económicos que atrajeron migrantes regionales de diversas procedencias a la zona del litoral del norte uruguayo desde el siglo XIX. Destacando al ejemplo de la industria saladeril de la zona donde en sus últimos años "más de la mitad de este ganado procedía de Entre Ríos y Corrientes", él sostiene que:

[...] el tráfico fluvial que confluía hacia el puerto sanducero y el incipiente desarrollo agrícola e industrial [...] fueron todos factores que polarizaron la afluencia de capitales y de inmigrantes. [...] A todo este desarrollo vino a agregarse la importante inversión británica del ferrocarril [...] la carga principal fue, durante muchos años, el ganado que se transportaba inclusive desde Rio Grande do Sul y Corrientes a los saladeros de Paysandú (CAMPAL, 1970, p.14-15)

El mismo autor describe al entorno cultural de los trabajadores que esta actividad económica trajo al departamento de Paysandú en la zona litoral del norte uruguayo:

Esta población constituida en su mayor parte por "orientales", pero también por entrerrianos, correntinos y riograndenses, estos últimos negros y mulatos que aún trabajaban como esclavos o semi-esclavos al servicio de sus amos "gaúchos" estancieros de la mitad oriental del departamento. La mayoría de los paisanos hablaba una mezcla de español, guaraní y portugués, lenguaje tri-nacional que se mantuvo vivo mientras perduró la actividad de los saladeros, en cuyos corrales y faenas se congregaban ganados y trabajadores de tres países. En sus fogones corrían leyendas, relatos y canciones de las dos bandas del Uruguay, desde São Borja y Santo Tomé hasta Fray Bentos y Gualeguaychú. Eso explica que Ayestarán haya podido recoger en Paysandú, hacía 1940, polkas y milongas cantadas [...] por viejos troperos de los saladeros. (CAMPAL, 1970, p.17-18)

Dentro de la grabaciones realizadas por musicólogo uruguayo Lauro Ayestarán en Paysandú en los años 1940, citadas por Campal, son piezas tocadas en acordeón de una hilera y cantadas por José Núñez el día 24 de setiembre, 1946 en "los arrabales de la ciudad de Paysandú". En esa fecha el Sr. Núñez "confesó que hacía muchos años que había cumplido los 85". (AYESTARÁN, 1997, p.52) [Figura 3]

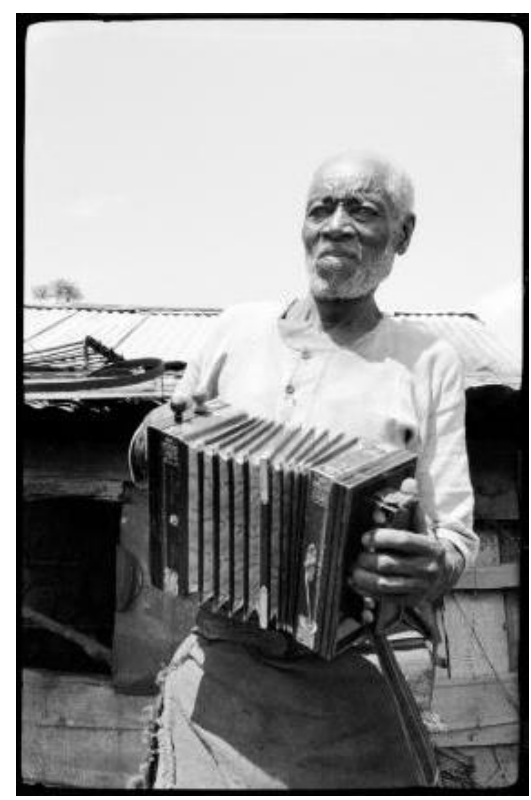


Figura 3 - José Núñez, 24 de setiembre, 1946, Paysandú (Foto: Lauro Ayestarán) Fuente: Centro de Documentación Musical Lauro Ayestarán

Acordeonista sanducero Marcelo Fagúndez, integrante del conjunto La Sinfónica de Tambores, viene de una familia de varias generaciones de acordeonistas populares, uno de los más destacados siendo el "Bocha" Fagúndez autor de la Polca del Cerro Chato y otros temas conocidos dentro de este género musical regional. Las observaciones de Marcelo sobre las raíces de su familia sirven para ilustrar las dinámicas descritas por Campal de los flujos migratorios regionales a la zona litoral del norte uruguayo. Según Fagúndez:

Yo no sé de donde proviene, porque no sé si mis abuelos o mi bisabuelo vendrían de algún lado que no sea del Uruguay, ¿no? Porque la familia Fagúndez es brasilero [...] le pregunto a mi viejo y creo que un abuelo de él tocaba. No sé muy bien como es la cosa, pero por ahí viene, por ahí viene. [...] porque hay Fagúndez Da Silva y hay Fagúndez de otro apellido también que son todos de la misma parentela y por ahí. Se comenta que viene de por ahí, sí [...] Sí, toda la zona. Y todavía afuera, del interior. Gente que venía, y debe ser cierto porque antes venían grandes grupos de familias y llegaban ahí y se formaba un pueblo, y vivían y se extinguían en la zona no más. [...] Unos nada más. Ahora hay Fagúndez por todos lados, pero tampoco somos parientes. Son Fagúndez de otros lados. El que no toca la acordiona no es Fagúndez de la parentela, o sea que vos preguntás, por ejemplo, "¿Vos sos Fagúndez? ¿Qué sos del Fagúndez que toca el acordeón? ", "Ah, ese es fulano...es tío mío o yo soy el sobrino de él..." Se vinculan, si no ni sabés. Ni sabés. (FAGÚNDEZ, 2002, p.3)

Acordeonistas tacuaremboenses Díaz y Roldán ambos tiene sus raíces familiares en el este del departamento de Salto, zona de presencia histórica de brasileños. Los dos músicos no saben con exactitud el origen nacional de sus antepasados. Según Díaz:

Nosotros somos descendientes de, de familia de mi padre era de ahí departamento de Mataojo de Salto, ellos vinieron de ahí ¿no? Esa parte de Mataojo, esa parte. Mataojo, porque está el Mataojo Chico, y el Mataojo Grande. Era Mataojo Chico, departamento de Salto, esa zona ya pertenecía a Salto, y mi familia, mis viejos eran todos de departamento de Salto [...] Mirá, lamentablemente, no sé, no sé, la parte de la procedencia de ellos no sé. (DÍAZ, 2002, p.10)

Roldán [Figura 4], quien en su vida artística el papel de sus raíces familiares son fundamentales, cuenta que:

Mi padre nació en Puntas de Arerunguá (Salto), y (de) chico lo llevaron para Colonia Lavalleja, departamento de Salto [...] La familia de mi madre era de Salto también, de la campaña de Salto. Pereira (de apellido). También había músicos ahí, que tocaba la guitarra. [...] Por parte de los Pereira. Este, y, mi padre aprendió a tocar el acordeón de muy gurí, ah. Cuando él tenía diez o doce años ya tocaba temas que aprendió con la abuela de él, ¿no? Que le enseñaba en la acordeón de una hilera. [...] Viene a ser mi bisabuela. [...] Seguro, si, de por ahí, eran oriundos de ahí (zona de Colonia Lavalleja). (ROLDÁN, 2003, 2010)

El acordeonista agrega que:

No, no, yo no conocí ni mis abuelos. [...] Si, los temas que ella le enseñó a mi padre, mi padre los conservé toda la vida en el repertorio de él, y yo se los recopilé de él y seguí tocándolos hasta ahora, ¿no? E incluso he grabado la mayoría de ellos. 
[...] Bueno, sobre mi árbol genealógico nunca pude descubrir nada [...] por esa zona de la Argentina, por ahí hay mucho Roldán, y yo no sé si son parientes o no [...] Bueno, eran mazurcas, chotis, habanera (la música de su padre y abuela) (ROLDÁN, 2003, p.5-6)

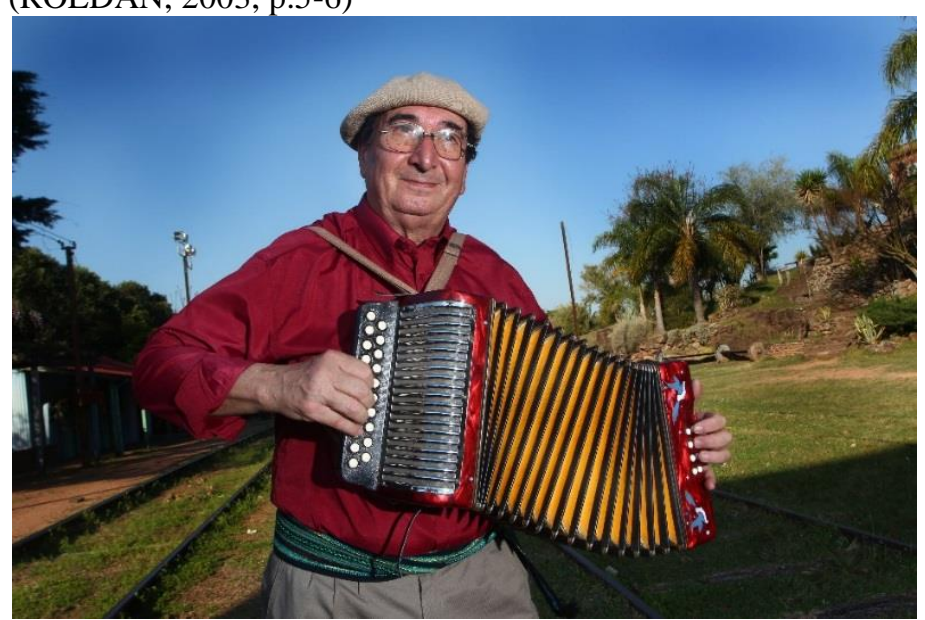

Figura 4 - Walter Roldán (Tacuarembó, 2013) Foto: Federico Estol

Acordeonista artíguense, Washington Montes, debe la presencia de sus antepasados en la frontera a la iniciativa del gobierno central uruguayo de extender su poder político-militar a su frontera norteña con el Imperio de Brasil. Según Montes:

(Somos descendientes) de españoles [...] por los dos lados. Españoles por los dos lados, sí. [...] Mis abuelos, ellos vinieron para acá, eran colonos ¿no? Inclusive mi bisabuelo, tatarabuelo por ahí fueron los primeros en venir para acá, fueron colonizadores de la ciudad. Entonces ellos se dedicaban a otra cosa [...] Bueno, se dedicaban a la ganadería, la agricultura, e inclusive tengo mi bisabuelo que fue general acá del Ejército, Santiago Montes, inclusive hay hasta una calle con el nombre de él acá. Bueno, él estudió, fue uno de los estudiosos de la familia, pero los otros...todos siempre también andaban en función de la música ¿no? Hacían sus quehaceres pero les gustaba la música y era una familia de músicos. Todo el mundo que más que menos alguna cosa ha tocado (MONTES, 2002, p.1, 7)

La transmisión oral mediatizada es de larga data en esta tradición musical. Los informantes afirman que desde la introducción y difusión de discos de $78 \mathrm{rpm}$ en el norte uruguayo en la primera mitad del siglo XX la tecnología ha sido una fuente importante de aprendizaje musical "de oído". En su gran mayoría estos discos 78 provenían de Argentina, Brasil y otros orígenes internacionales. Según Roldán:

La maxixa que era un ritmo que se usaba mucho en la campaña acá de Tacuarembó y de Salto por la influencia de Brasil que tocaban mucha maxixa [...] se difundía la maxixa en discos de 78 y [...] los músicos tocaban esas cosas. Ahora, mi padre tenía muchas maxixas que él recopilaba de otros acordeonistas [...] la mayoría ni sabía que nombre tenía, y muchas tal vez fueron sacadas del algún disco 78 de aquellos muy antiguos por que antes se usaba acá. En mi barrio en los alrededores se usaba bailar todos los fines de semana en casas de familia y muchas veces no tenían un músico para que tocara y ponían una, ellos decían que era una Victrola, otros le dan otro nombre pero yo me acuerdo que era una valijita negra chiquita y ponían un disco allí. Había uno encargado, y ahí un tema de cada lado del disco, discos 78 revoluciones y ahí se escuchaba mucha música de esas bailables. Maxixa, a veces 
entraba alguna cosa brasilera, algún pasodoble también español también tenía. (ROLDÁN, 2010, p.6-7)

Sobre la composición de los discos 78 que circulaban en el entorno social de su juventud en la ciudad de Tacuarembó, Roldán recuerda:

Había mucho argentino [...] Canaro, una cantidad de orquestas grandes tocaban temas, tocaban polcas, tocaban maxixas. Y eso que era bailable y era adaptable a la acordeón lo aprendían. Muchas veces el acordeonista con un instrumento con tan pocos recursos como es una acordeón de dos hileras, que sólo 21 teclas que no tiene semitonos muchas veces, tenía que, a veces, algunas notas saltaban ¿no? y [...] lo adaptaba a su acordeón, a su instrumento y lo tocaba igual, porque muchas veces la gente al ser un tema de conocimiento público que lo pasaran por la radio por ejemplo en los bailes la gente lo pedía. (ROLDÁN, 2016, p.15)

Varios años después, cuando Roldán tenía el oficio de animar fiestas bailables en la región con su orquesta él recuerda que esa influencia mediática transfronteriza continuó incidiendo en los repertorios musicales empleados para complacer los gustos de los públicos:

$\mathrm{Si}$, si, se escuchaba (la música gaúcha por radio) y gustaba también en los bailes, ¿no? Yo siempre las mezclé porque en los bailes era una música alegre que siempre gustaba, samba, un choro, forró, contrapasso, "arrastapie" que dicen, también. Todo ese tipo de música brasileña hacían porque gustaba, pero también iba lo nuestro. (ROLDÁN, 2003, p.18)

Acordeonista Washington Montes [Figura 5], en la ciudad de Artigas, refleja sobre la manera en que la ubicación geográfica de su ciudad en la línea divisoria con el Brasil y la recepción constante de influencias transfronterizas han moldeado a su actividad musical:

[...] acá no se dedica a un género sólo [...] son varios géneros porque somos músicos fronterizos [...] El músico siempre tiene que adaptarse a las dos cosas, tiene que ser internacional [...] el músico va adquiriendo conocimiento porque la situación te obliga [...] y uno naturalmente lo va asimilando. [...] siempre intentar actualizándonos de lo que la gente consume. (MONTES, 2016)

Para ilustrar a la influencia mediática brasileña en la frontera, Simões Larbanois observó en 1970 que en la ciudad fronteriza de Rivera:

[...] Hay zonas enteras de la ciudad donde sólo se escucha la radioemisora de Livramento [...] Las canciones brasileñas, de música contagiosa, son las que más se cantan en la frontera, y en Carnaval jamás se oye una canción en español en la calle, en los tablados, o en los bailes. (SIMÕES LARBANOIS, 1970, p.45)

Sobre el funcionamiento de la transmisión oral mediatizada en su entorno social varias décadas atrás, Montes recuerda:

En aquel momento se hacía así, por ejemplo, los músicos, no como ahora que tenemos toda la ventaja de la electrónica ¿no? En aquel tiempo los músicos tocaban instrumentos acústicos, y bueno, los medios de difusión que habían era la radio [...] entonces el músico tenía que, para aprender la música o escuchar en la radio y se grababa en la mente, y después la pasaba para el instrumento, o con los propios otros compañeros ¿no? Siempre uno sabía un tema y le pasaba al otro compañero y este le pasaba al otro, y bueno, se estilaba así. Esa era la manera, el músico le preguntaba "¿Conocés tal pieza así", "Sí, yo la sé", entonces ese la pasaba al compañero, y entonces ahí vas fortaleciendo el repertorio ¿no? y no se estilaba tocar un tipo de 
música, un estilo de música, no, era cuanto más amplio fuera el repertorio del músico mejor [...] Exactamente, todo el tipo de música que se conocía en la región, el músico lograba poder tocar esa música mejor para él. [...] todo eso, la maxixa, el baião, el xaxado, todo eso, que son músicas de acá de la frontera ¿no? que vienen del lado de Brasil, y el chorinho, el samba, todos son músicas que se tocaban en el momento ¿no? Allá en el momento de los 60, 60 y pico predominaba el baião ¿no? Música nordestina que es una música buenísima (MONTES, 2002, p.4)

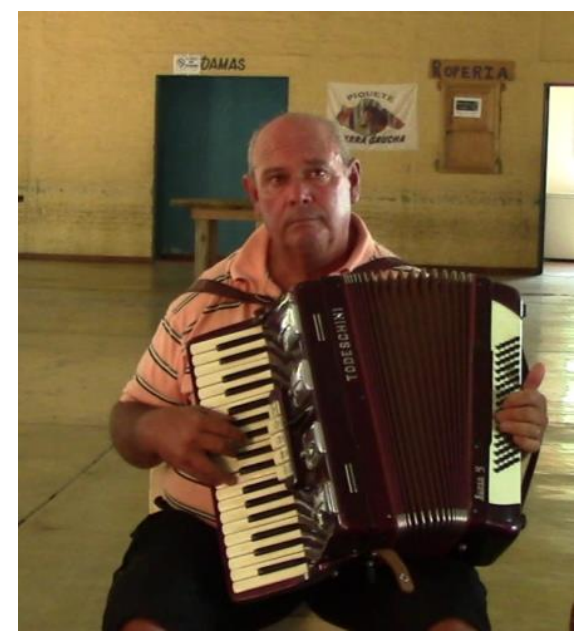

Figura 5 - Washington Montes (Artigas, 17 Marzo, 2016) Foto: José A. Curbelo

De la misma forma, acordeonista sanducero Marcelo Fagúndez, radicado en la frontera fluvial con Argentina, describe la forma que él incorporó al chamamé a su repertorio musical originalmente compuesto de piezas en ritmo de polca, mazurca, etc. heredadas de su familia. Destaca al papel instrumental de la radio en la transmisión oral mediatizada de esta influencia musical transfronteriza:

[...] siempre me gustó el chamamé [...] escuchaba en las radios porque nunca vi una persona que dijera que "se toca así", un maestro, porque realmente nunca lo vi en vivo [...] Grabamos en casete, chamamés que pasaban (en las radios argentinas) [...] chamamé lo sacábamos de ahí, de la radio. (FAGÚNDEZ, 2002)

Además de las influencias transfronterizas de carácter inmaterial, el papel de la frontera es enfatizado por los informantes como un lugar de adquisición de bienes materiales fundamentales a esta tradición musical, principalmente instrumentos de fuelle. Según acordeonista tacuaremboense Euclides Díaz (2002), "Antiguamente, las acordeones de dos hileras fueron traídas de la frontera [...] No había casa de música, que vendiera acordeón no había [...] en Tacuarembó. Justamente, sólo de los contrabandistas, que los contrabandistas eran los que traían la acordeón". Roldán (2003, p.18) también recuerda que, "En Santana se compraba acordeones. Se elegía acordeones muy buenas y eran baratas también".

Fagúndez cuenta sobre la forma que él adquirió su primer acordeón de tres hileras en Argentina: 
Nosotros teníamos información que en Corrientes, en Santa Fe, en todos esos lugares ahí (había), porque los conjuntos todos los que hemos escuchados son de ahí. [...] pero decidimos ir a Buenos Aires porque yo había estado trabajando en Buenos Aires y las veía en la vidriera y quedás chocho. Entonces cuando tuvimos la oportunidad de ir fuimos a Buenos Aires a comprar [...] (FAGÚNDEZ, 2002, p.1112)

Otro dinámica transfronteriza citada por los informantes es la circulación de músicos en espacios de frontera. Para varios de los informantes el hecho de soler animar fiestas en los dos lados de la frontera ha sido un factor importante en sus vidas como músicos. Sus historias reflejan, "el hábito común de los pobladores de zonas fronterizas de [...] divertirse de un lado u otro del límite". (GRAVINA, 1970, p.26)

Washington Montes tiene recuerdos sobre tocar por el lado brasileño de la frontera cuando acompañaba a su padre en amenizar bailes en Artigas y la región:

[...] tengo uno muy lindo que en la época que nosotros viajábamos, o sea, nos trasladábamos en camiones para ir a tocar, por ejemplo si teníamos que ir a Paso del León, que era un lugar que a nosotros nos contrataban seguido, [...] a mi padre, y yo iba con él y con otros músicos. Tengo una (anécdota) muy importante, muy linda que siempre me recuerdo, que nosotros teníamos que pasar, nosotros tocamos en el lado de Brasil, como si fuera acá en Artigas pero tocamos en el lado de Quaraí. ¿Pero qué pasa? Llegamos hasta el lugar, hasta la frontera del lugar, para pasar teníamos que pasar en bote [...] para llegar al lugar, que era como una estancia, un almacén de campaña, llegábamos al río, pasábamos el rio en bote, cargando los instrumentos, todo. Del otro lado había que hacer cinco, seis kilómetros para llegar hasta el lugar, entonces ahí seguíamos en carretilla, a caballo ahí, a caballo con la carretilla. Venía una persona a buscar. Y entonces yo me acuerdo que un cierto día que fuimos a ese lugar - fuimos varias veces ahí - íbamos yendo, mi padre era vivo todavía en la época, y el caballo disparó, nosotros íbamos arriba en la carretilla, el caballo se asustó de no sé de qué. Disparó y llevábamos la cantina ahí también ¿viste? para la hora del baile: las bebidas, galletitas, cigarrillos, y los instrumentos. Y el caballo disparó sólo, se fue sólo porque nosotros nos tiramos de la carretilla, había un monte ahí. Y yo me acuerdo que todo el mundo nos tiramos y, bueno, quedando mirando de lejos, y aquello saltaba, acordeón para un lado, pandeiro por el aire, galletitas. Entonces eso fue una cosa que me quedó muy marcado y después por la noche se seguía con el baile no más. No había luz, o sea, energía eléctrica, era todo a farol ¿no? los instrumentos eran todos acústicos y así eran los bailes en esa época, una cosa muy linda, muy natural aquello ¿no? Y hoy en día, a pesar de no ser tan lejos porque yo no soy tan viejo, tengo 42 años recién, tan cerca ahí pero parece que era otro país, parece que era otra cosa, hoy ha cambiado [...]. (MONTES, 2002, p.10)

Bandoneonista sanducero Jorge Medina recuerda sobre los tres años que él tocó en bailes de escuela en la campaña entrerriana, frontera con el Uruguay, con un trio juvenil armado por su profesor Juan Carlos Rubiolo que tenía por nombre "Los Sobrinitos de Donald", y era compuesto de guitarra, bandoneón y acordeón a piano. Su relato da un ejemplo elocuente de la importancia que los bailes sociales podían tener para la sociabilización de comunidades geográficamente dispersas en zonas rurales de la región:

En ese tiempo vos llegabas a una escuela que te contrataba y vos llegabas de día y era todo campo. Nosotros sentíamos que los padres de nosotros decían "¿Y qué 
vamos a venir acá que si no hay - no ves ni una casa?" Vos sabés que es una cosa impresionante ¿no? Íbamos para la escuela adentro que nos daban la cena y cuando salíamos para afuera para ir a tocar estaba lleno de gente, lleno, pero una cosa impresionante, y todos (los bailes) iguales. Salía para afuera y era camioneta, eran camiones [...] Seguro, venían de todos lados, se juntaban y eso nos pasó en varios lados, llegábamos y era todo desierto, había por ahí una casa cada tanto ahí, y gracias a Dios tocamos muchos lugares [...]. (MEDINA, 2016, p.7)

También, bandoneonista Ernesto Farias recuerda sobre sus andanzas en el Brasil:

Hace más o menos 50 años que estoy en la frontera. [...] en 50 años recorrí por todos lados tocando bandoneón. Empecé tocando en Montevideo y después cuando me vine para acá tocando el bandoneón en bailes y eso durante muchos años, todo lo que fue baile, aquí y en el otro lado de la frontera de Río Branco en Jaguarão [...] Posiblemente en el Brasil escuchan más al bandoneón que acá. [...] Ya, para el Brasil, ya he ido a varios eventos y encuentros de bandoneones, en Caçapava, Canguçu, el último que estuve fue en Passo Fundo [...] y allá la gente escucha el bandoneón, y hay bandoneonistas, y hay bandoneonistas buenos en el Brasil, como acá pero hay más bandoneonistas en el Brasil en los pueblos que acá en el Uruguay. En Caçapava, por ejemplo, yo encontré a 30 bandoneonistas, en todo Cerro Largo capaz que no hay 10. (FARIAS, 2016, p.1)

Desde su niñez, Walter Roldán tocó en bailes en la ciudad de Tacuarembó y luego pasó a tocar bailes en la región rural de los departamentos de Tacuarembó, Salto, y Rivera, zonas de histórica influencia luso-brasileña. El área geográfica donde él se desempeñaba como acordeonista en bailes es resumido por él como:

Más bien [...] acá en el norte ¿no? Dentro de Tacuarembó, Salto, algunas zonas de
Rivera, en Rivera entraba mucho, y en Salto también por Mataojo, Pepe Núñez,
Cerro Travieso, Cuchilla Casa de Piedra, toda esa zona, Carumbé. Después para el
lado de Rivera: por Buena Orden, Los Mimbres, Minas de Corrales, Minas de San
Gregorio, todo eso, fui a Curtina en algunas oportunidades, San Gregorio [...]
(ROLDÁN, 2002, p.11)

Roldán delimita geográficamente los circuitos de circulación de ejecutantes de acordeón y bandoneón que tocaban el estilo y repertorio tradicional del cual él es un heredero con la predominancia del ritmo de polca:

El norte del Río Negro, las regiones de Salto, parte de Paysandú, esas zonas, y Artigas, parte de Artigas [...] porque acordeonistas de acá de Tacuarembó, acordeonistas de Salto, recorrían toda esa zona tocando y se tocaba de esa manera [...] (la) polca, yo digo que es un ritmo regional, no abarca todo el Uruguay. Es esta parte. [...] Es una música regionalista de acá porque se transformaron los ritmos. No es lo mismo una polca del sur, traída por los inmigrantes, que una polca de acá del norte del Río Negro. [...] Nosotros tenemos la polca con un ritmo totalmente distinto al que se toca en el Brasil. (ROLDÁN, 2016)

A través de las narrativas de sus propios intérpretes sobre sus vivencias personales y las de sus antepasados, este artículo demostró que la música de acordeón y bandoneón del norte uruguayo ha sido influenciada por dinámicas transfronterizas regionales a lo largo de su historia, transformando su desarrollo. Entendiendo la fronteras uruguayas como "áreas de influencia que exceden al ámbito territorial fronterizo y cuya incidencia atraviesa 
notoriamente el entramado social" (DOMINZAIN, 2011, p.5), en el caso de esta música vemos la afirmación de Machado de Oliveira (2005, p.380-381) que, "las fronteras (son) territorios singulares. Son singulares en relación al territorio-nación y singulares entre si cada frontera es una frontera".

La diversidad social y cultural de la región de frontera del norte uruguayo y los flujos migratorios transfronterizos que ha recibido a través de la historia son reflejados en la transmisión intrafamiliar y transmisión vía oralidad mediatizada que son los dos vectores más importantes para la reproducción social de la música de acordeón y bandoneón del norte uruguayo.

\section{Referencias}

AROCENA, F.; GAMBOA, M. Marco conceptual e hipótesis de trabajo para la regionalización cultural. In: AROCENA, F. (Org.). Regionalización Cultural del Uruguay. Montevideo: Universidad de la República, 2011. p. 17-77.

AYESTARÁN, L. Teoría y Práctica del Folklore. Montevideo: Arca. 1968.

AYESTARÁN, L. El folklore musical uruguayo. Montevideo: Arca Editorial, 1997.

CAMPAL, E.; PEÑA, J. Reseña geográfica. Paysandú: Los Departamentos 11. Editorial Nuestra Tierra: Montevideo. 1970.

CLEMENTE, I. La región de frontera Uruguay-Brasil y la relación binacional: Pasado y perspectivas, Revista Uruguaya de Ciencia Política, Montevideo, - Vol. 19 N¹, p.165-184, 2010. Disponível em: http://cienciassociales.edu.uy/departamentodecienciaspoliticas/wpcontent/uploads/sites/4/2013/archivos/isabel\%20clemente.pdf. Acesso em: 25 jul. 2017.

COOLEY, T., Making Music in the Polish Tatras: Tourists, Ethnographers, and

Mountain Musicians. Bloomington: Indiana University Press, 2005. 
DE LARROBLA, Nieves A., Justino Jiménez De Aréchaga, Anunciación Mazella De Bevilacqua, Brenda Varsi De López, Olga Rienzi, and Anáis Pereira. Estudio Sobre El Problema Idiomático Fronterizo. Montevideo: Academia Nacional De Letras: Comisión Para El Estudio Del Español En La Zona Fronteriza, 1982.

DÍAZ, E. Euclides Díaz: depoimento [mar. 2002] Entrevistador: J. Curbelo. Tacuarembó, Uruguai. 1 arquivo digital. Entrevista concedida a projeto de pesquisa independente.

DÍAZ, E. Euclides Díaz: depoimento [jul. 2016] Entrevistador: J. Curbelo. Tacuarembó, Uruguai: UFPEL, 1 arquivo digital. Entrevista concedida à pesquisa para Dissertação de Mestrado do PPGMP da UFPel.

DOMINZAIN, S., et al. Música y audiovisuales en ciudades de fronteras. Montevideo: FHUCE-MEC-AECID, 2011. p. 19-41.

DUNKEL, M. Liner Notes. Bandoneón Pure: René Marino Rivero. Washington, D.C.: Smithsonian Folkways Recordings. 1993.

ELIZAINCÍN, A. Dialectos en contacto: Español y portugués en España y América. Montevideo: Arca, 1992.

FAGÚNDEZ, M. Marcelo Fagúndez: depoimento [mai. 2002] Entrevistador: J. Curbelo. Paysandú, Uruguai. 1 arquivo digital. Entrevista concedida a projeto de pesquisa independente.

FAGÚNDEZ, M. Marcelo Fagúndez: depoimento [jul. 2016] Entrevistador: J. Curbelo. Paysandú, Uruguai: UFPEL, 1 arquivo digital. Entrevista concedida à pesquisa para Dissertação de Mestrado do PPGMP da UFPel.

FARIAS, E. Ernesto Farias: depoimento [mar. 2016] Entrevistador: J. Curbelo. Río Branco, Cerro Largo, Uruguai: UFPEL, 1 arquivo digital. Entrevista concedida ao projeto Paraformal na Fronteira do Laboratório de Urbanismo da UFPel. 
FARIAS, E. et al. Ernesto Farias et al.: depoimento [fev. 2016] Entrevistador: J. Curbelo. Río Branco, Cerro Largo, Uruguai: UFPEL, 1 arquivo digital. Entrevista concedida à pesquisa para Dissertação de Mestrado do Programa de Pós-Graduação de Memória Social y Patrimônio Cultural da UFPel.

FELD, S., Jazz Cosmopolitanism in Accra: Five Musical Years in Ghana. Durham: Duke University Press, 2012.

FORNARO, M. El "Cancionero Norteño": Música Tradicional Y Popular De Influencia Brasileña En El Uruguay. Montevideo: Instituto Nacional Del Libro, Ministerio De Educación Y Cultura, 1994.

FORNARO, Bordolli Marita. La radiodifusión y el disco: un análisis de la recepción y adquisición de música popular en Uruguay entre 1920 y 1985. In: CONGRESO INTL. DE LA SOCIEDAD IBÉRICA DE ETNOMUSICOLOGÍA, 8, 2004, Zaragoza. Revista Aragonesa de Musicología. XXI. Zaragoza: Institución Fernando el Católico Excma. Diputación de Zaragoza, 2005.p. 143-155

FORNARO, Bordolli Marita. Teoría y terminología en la historia de la música popular uruguaya: los primeros cincuenta años. In: CONGRESO DE LA RAMA LATINOAMERICANA DE LA IASPM, 9., 2010, Caracas. ¿Popular, pop, populachera? El dilema de las músicas populares en América Latina, Montevideo: IASPM-AL y EUM, 2011. p. $38-51$

GRAVINA, L. Río Branco. Cerro Largo: Los Departamentos 18. Editorial Nuestra Tierra: Montevideo. 1970.

MACHADO DE OLIVEIRA, T. Tipologia das relações fronteiriças: Elementos para o debate teórico-práticos. Território sem limites: Estudos sobre fronteiras; Editora UFMS. Campo Grande, MS. Disponível em: http://www.retis.igeo.ufrj.br/wp-content/uploads/2011/07/2005Territorio-sem-limites-TCMO.pdf Acesso em: 25 jul. 2017. 
MEDINA, Jorge. Jorge Medina: depoimento [jul. 2016] Entrevistador: J. Curbelo. Paysandú, Uruguai: UFPEL, 1 arquivo digital. Entrevista concedida à pesquisa para Dissertação de Mestrado do PPGMP da UFPel.

MEDINA, J. Jorge Medina: depoimento [mai. 2002] Entrevistador: J. Curbelo. Paysandú, Uruguai, 1 arquivo digital. Entrevista concedida à pesquisa independente.

MENDOZA DE ARCE, D. Sociología del folklore musical uruguayo. Montevideo: Editorial Goes, 1972.

MONTES, Washington, et al. Washington Montes, et al.: depoimento [mar. 2016] Entrevistador: J. Curbelo. Artigas, Uruguai: UFPEL, 1 arquivo digital. Entrevista concedida ao projeto Paraformal na Fronteira do Laboratório de Urbanismo da UFPel.

MONTES, W., et al. Washington Montes, et al.: depoimento [ago. 2002] Entrevistador: J. Curbelo. Artigas, Uruguai, 1 arquivo digital. Entrevista concedida à pesquisa independente.

OSTUNI, J. Una cultura cuestionada. Paysandú: Los Departamentos 11. Editorial Nuestra Tierra. Montevideo. 1970.

PADRÓN FAVRE, Oscar. El proceso de creación de los departamentos/ Historia cultural de las regiones. In: AROCENA, F. (Org.). Regionalización Cultural del Uruguay. Montevideo: Universidad de la República, 2011. p. 45-130.

PELlEGRINO, A. Migraciones: una mirada desde los Censos. Nuestro Tiempo 12. Comisión del Bicentenario. Montevideo. 2013.

PI HUGARTE, R.; VIDART, D. El legado de los inmigrantes I. Editorial Nuestra Tierra. Montevideo. 1969.

RADAKOVICH, Rosario. Lo nuestro, lo local, en los gustos musicales de frontera. In: DOMINZAIN, S., et al. Música y audiovisuales en ciudades de fronteras. Montevideo: FHUCE-MEC-AECID, 2011. p. 19-41. 
REAL DE AZUA, C. Uruguay, ¿una sociedad amortiguadora?

Ediciones de la

Banda Oriental. Montevideo, 1984.

RIAL, J. "Uruguay. La génesis de un país urbano macrocefálico" Eure, 31 (1984), 9-28, accessed July 2, 2012 http://www.eure.cl/numero/uruguay-la-genesis-de-un-pais-urbanomacrocefalico/

ROLDÁN, W. Walter Roldán: depoimento [jul. 2016] Entrevistador: J. Curbelo. Tacuarembó, Tacuarembó, Uruguai: UFPEL, 1 arquivo digital. Entrevista concedida à pesquisa para Dissertação de Mestrado do Programa de Pós-Graduação de Memória Social y Patrimônio Cultural da UFPel.

ROLDÁN, W. Walter Roldán: depoimento [jan. 2003] Entrevistador: J. Curbelo. Tacuarembó, Tacuarembó, Uruguai, 1 arquivo digital. Entrevista concedida à pesquisa independente.

ROLDÁN, W. Walter Roldán: depoimento [jun. 2010] Entrevistador: J. Curbelo. Tacuarembó, Tacuarembó, Uruguai, 1 arquivo digital. Entrevista concedida à pesquisa realizada por Smithsonian Folkways Recordings.

SIMÕES LARBANOIS, A. Lenguaje fronterizo. Los Departamentos: Rivera. Vol.03, Editorial "Nuestra Tierra", Montevideo, 1970.

TEIXEIRA DE SCIRGALEA, L., PAMPARATO DE UGARTEMEDÍA, O., TAFERNABERRY DE PIROTTO, S. Los hombres. Salto: Los Departamentos 8. Editorial Nuestra Tierra. 1970.

TURMAnIDZE, T. Buffer States: Power Policies, Foreign Policies and Concepts. New York: Nova Science, 2009.

ZUMTHOR, P. Permanencia de la voz. In: El Correo: De la palabra viva a la escrita. Agosto 1985. Paris: UNESCO. 1985. 